\title{
MODELAGEM DA MARÉ METEOROLÓGICA UTILIZANDO REDES NEURAIS ARTIFICIAIS: UMA APLICAÇÃO PARA A BAÍA DE PARANAGUÁ - PR, PARTE 2: DADOS METEOROLÓGICOS DE REANÁLISE DO NCEP/NCAR
}

\author{
MARILIA MITIDIERI F. DE OLIVEIRA ${ }^{1}$, NELSON FRANCISCO F. EBECKEN ${ }^{1}$, \\ ISIMAR DE A. SANTOS ${ }^{2}$, CLAUDIO F. NEVES ${ }^{3}$, LUIZ P. CALOBA ${ }^{4}$ e \\ JORGE LUIZ F. DE OLIVEIRA ${ }^{5}$
}

\author{
${ }^{1}$ Universidade Federal do Rio de Janeiro, COPPE/Programa de Engenharia Civil \\ E-mail: mariliamitidieri@globo.com \\ ${ }^{2}$ Universidade Federal do Rio de Janeiro, IGEO/UFRJ/Departamento de Meteorologia \\ ${ }^{3}$ Universidade Federal do Rio de Janeiro, COPPE/Programa de Engenharia Costeira \\ ${ }^{4}$ Universidade Federal do Rio de Janeiro, COPPE/UFRJ/Programa de Engenharia Elétrica \\ ${ }^{5}$ Universidade Federal Fluminense, IGEO/UFF/Departamento de Geografia
}

Recebido Maio 2005 - Aceito Março 2006

\begin{abstract}
RESUMO
A variabilidade do nível do mar observado e a maré meteorológica na Baía de Paranaguá-PR foram analisadas, neste trabalho, com os dados maregráficos utilizados na Parte 1 e os dados meteorológicos de reanálise do "National Centers for Environmental Prediction" (NCEP) e do "National Center Atmospheric Research" (NCAR) pontos de grade no oceano, próximos ao local de estudo, referentes ao mesmo período. As componentes de alta freqüência contidas nos dados de reanálise foram retiradas com o filtro passa-baixa de Thompson, descrito na Parte 1, adaptado para intervalos de 6 horas. Analisou-se as influências das variáveis meteorológicas mais remotas, nas sobre-elevações e abaixamentos do nível do mar observado, utilizando dados de reanálise de pressão e vento. Conforme descrito na Parte 1, as séries foram analisadas, estatisticamente, no domínio do tempo e da freqüência. A série maregráfica filtrada de Cananéia (SP), utilizada para verificar a existência de correlação com a série de Paranaguá, confirmou os estudos de Mesquita (1997) para o litoral Sudeste. Essa correlação foi verificada devido à proximidade da estação de Cananéia ao ponto de grade relativo à pressão. A Rede Neural Artificial (RNA) desenvolvida na Parte 1 foi, então, utilizada com os dados de reanálise, mantendo-se a mesma arquitetura de rede com as máximas correlações entre as variáveis de entrada e saída, ajustando-se os parâmetros de taxa de aprendizado e momento para alcançar o melhor desempenho. Os resultados obtidos com ambas as fontes de dados foram comparados e a eficiência da rede foi semelhante à Parte 1 para as simulações de $6 \mathrm{~h}$ e $12 \mathrm{~h}$. Para as simulações de $18 \mathrm{~h}$ e 24h, os resultados foram inferiores como os encontrados para a estação de superfície, sugerindo também, o desenvolvimento de outras arquiteturas de rede, visando melhorar as previsões para períodos maiores. Os resultados obtidos com os dados de reanálise sugerem a sua utilização na falta de estações meteorológicas convencionais próximas a estações maregráficas.

Palavras-chave: Redes Neurais Artificiais, variabilidade do nível do mar, maré meteorológica, previsão de séries temporais e dados de reanálise.
\end{abstract}

\footnotetext{
ABSTRACT: METEOROLOGICAL TIDE MODELING USING AN ARTIFICIAL NEURAL NETWOK: AN APLICATION TO THE PARANAGUÁ BAY-PR: PART 2: NCEP/NCAR REANALYSIS METEOROLOGICAL DATA.

The variability of the observed sea level and the meteorological tide in Paranaguá Bay-PR was analyzed with the tide gauge station time series used in the Part 1 and reanalysis data set of the "National Centers for Environmental Prediction" (NCEP) and the "National Center Atmospheric Research" (NCAR), on some grid points over the oceanic area, near the Bay to the same period. The Thompson low-pass filter was adapted for 6 hours intervals to remove the high frequency oscillations present in teh reanalysis
} 
data set. Remote influence of the meteorological variables, in the rises and lowing of the coastal sea level, are analyzed, statistically, in the time and the frequency domain according to the Part 1 . Tide gauge station time series from Cananéia (SP), used to verify the correlation with Paranaguá data set, confirmed the Mesquita (1997) research to the southeastern coastal region. Correlation between the variability of the meteorological tide in both cities were made due to the point 1 is near Cananéia. Artificial Neural Network (ANN) with the same architecture developed in Part 1 was applied to the reanalysis data. The maxima correlations between the input/output vectors were also used, adjusting the learning rate and momentum for improving the algorithm to reach the best performance. As the Part 1, the network performed very well at 6 and 12 time lag simulations. The results to 18 and 24 time lag simulations were lower than these ones presented to the surface station, than these ones, suggesting also, others ANN architectures to improve the predictions for larger periods. The results suggest the using of reanalysis data where the lack of conventional station is significant.

Keywords: Artificial Neural Network, sea level variability, meteorological tide (surge), time series forecasting and reanalysis dataset.

\section{INTRODUÇÃO}

O presente artigo apresenta os resultados da modelagem de RNA na predição da variabilidade da maré meteorológica para o Porto de Paranaguá com dados de reanálises do NCEP/ NCAR, os quais foram utilizados no estudo das influências meteorológicas remotas na região em questão, correlacionandoos com essa variabilidade. Avalia-se, também, a utilização desses dados na ausência de dados meteorológicos de estação de superfície próxima à estação maregráfica.

Patrick et al. (2003) utilizaram um modelo de RNA na predição do nível do mar na região norte do Golfo do México, tendo como elementos de entrada as forçantes meteorológicas e astronômicas, utilizando dados de reanálise do NCEP/NCAR e saídas do modelo ETA de previsão do módulo do vento. Como na Parte 1, utilizou-se também o módulo do vento na predição da maré meteorológica na Baía de Paranaguá com somente dados de vento de reanálise.

A fim de compreender melhor as relações existentes entre a meteorologia local e remota, nas variações do nível do mar, os resultados estatísticos obtidos com os dados de Pontal do Sul (Parte 1) foram comparados com os resultados obtidos com dados de reanálise do NCEP/NCAR. Dessa forma, procurou-se responder as seguintes questões:

VTEventos meteorológicos remotos afetam, significativamente, a variabilidade da maré meteorológica no ponto em questão, já que a estação maregráfica encontra-se na Baía de Paranaguá?

VComo o nível do mar costeiro em Paranaguá responde às flutuações da pressão atmosférica nos pontos situados, tanto na costa como no oceano?

VTA arquitetura de rede desenvolvida na Parte 1 é capaz de prever a maré meteorológica, de forma satisfatória com dados de reanálise?

\section{DADOS E METODOLOGIAS}

\subsection{Dados}

Para estudar as influências remotas, na área da Baía de Paranaguá, foram utilizados dados meteorológicos de reanálise do NCEP/NCAR, compreendidos nas coordenadas geográficas: $25^{\circ} 00^{\prime}$ a $26^{\circ} 00^{\prime} \mathrm{S}$ de latitude e $46^{\circ} 00^{\prime} \mathrm{W}$ de longitude e limitada pela faixa litorânea que se estende do sul do Estado de São Paulo ao Estado do Paraná.

Os dados maregráficos do Porto de Paranaguá - Cais Oeste foram selecionados de 6 em 6 horas (hora local). Foram utilizados os dados de reanálise de pressão atmosférica, componentes zonal e meridional do vento, nos pontos de grade de $2.5^{\circ} \mathrm{x}$ $2.5^{\circ}$ e $1.817^{\circ} \times 1.817^{\circ}$ de latitude por longitude, respectivamente, nos horários de 00, 06, 12 e 18 UTC. Foram utilizados, também os dados referentes à previsão de maré e os boletins diários de previsão do tempo conforme descrito na Parte 1 .

A série maregráfica da cidade de Cananéia, disponibilizada via Web pelo Instituto Oceanográfico da Universidade de São Paulo - IO/USP, foi utilizada para comparar as séries filtradas das duas localidades litorâneas.

A Figura 1 mostra a região de estudo inserida no litoral Sudeste entre parte do Rio de Janeiro - RJ até a Ilha de Santa Catarina - SC, com a localização das estações maregráficas de Paranaguá e Cananéia, estação meteorológica de Pontal do Sul, bem como os pontos de reanálise 1 e $\mathbf{2}$, relativo a pressão atmosférica e vento, respectivamente. As características das reanálises do NCEP/NCAR são descritas, em detalhes, por Kalnay et al. (1996) e Kalnay et al. (2001).

\subsection{Metodologias}

As séries maregráficas e meteorológicas de reanálise foram filtradas com o filtro passa-baixa de Thompson, utilizando-se o mesmo procedimento descrito na Parte 1, porém, 


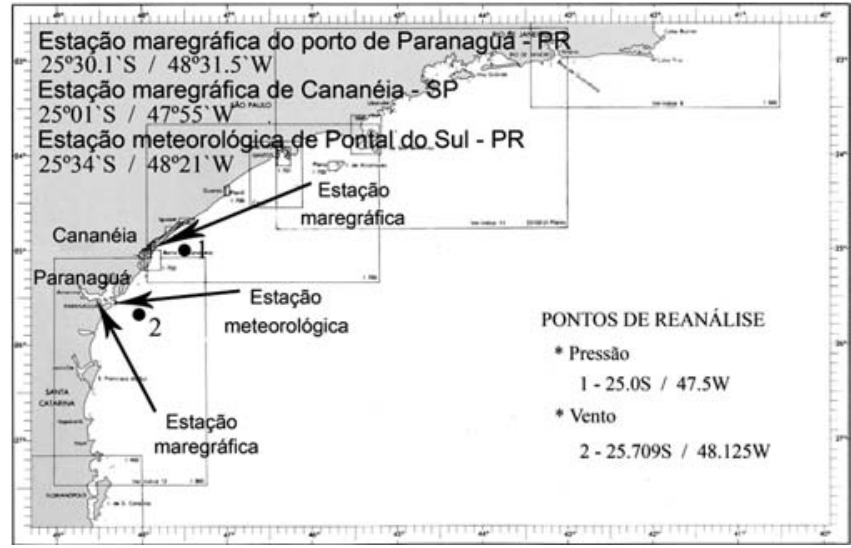

Figura 1 - Carta Náutica n 80/64 da DHN com as coordenadas geográficas das estações e pontos de reanálise.

com o número de pesos, $\mathrm{N}=20$ referentes aos dados com intervalos de 6 horas e freqüências de corte entre $38.4 \% 6 \mathrm{~h}$ e 67.2\% (Uaissone, 2004).

Os dados de pressão atmosférica de reanálise foram correlacionados com informações de superfície obtidas de cartas sinóticas do CHM. As componentes zonal e meridional do vento foram correlacionadas com o vento geostrófico, calculado após interpolação entre os pontos de pressão relativos à área oceânica em questão. Também foram calculadas as tensões zonal e meridional do vento.

Aplicou-se, também, o método clássico de séries temporais como descrito na Parte 1 (Moretim, 1987) referentes à tendência e sazonalidade das séries de maré e pressão (Calôba, 2002).

As relações existentes entre os processos atmosféricos $\mathrm{e}$ a variabilidade do nível do mar, observada na Baía de Paranaguá, foram estudadas, também, a partir de cálculos estatísticos no domínio do tempo e da freqüência, como especificado na Parte 1 , referente às séries obtidas através do NCEP/NCAR nos pontos $\mathbf{1}$ e $\mathbf{2}$.

Para a série maregráfica da cidade de Cananéia foram calculados os pesos do filtro passa baixa de Thompson, de acordo com as análises dos registros horários do nível do mar do ano de 1998, seguindo os procedimentos do método harmônico para a determinação das constantes harmônicas com o programa PACMARÉ (Franco, 1992). Os principais constituintes harmônicos foram utilizados no cálculo dos pesos, juntamente com o valor da freqüência inercial local.

Os dados maregráficos filtrados de Paranaguá e Cananéia foram comparados, uma vez que o ponto $\mathbf{1}$ de reanálise situa-se no ponto de grade próximo a Cananéia, pois segundo Mesquita (1997) a variabilidade do nível médio do mar, no litoral sudeste é bem semelhante.
As correlações calculadas com as séries tratadas indicaram os atrasos relativos à resposta do mar às perturbações atmosféricas. Como na Parte 1, as correlações máximas foram utilizadas como variáveis de entrada do modelo neural.

O módulo do vento também foi usado como variável de entrada na modelagem da maré meteorológica com dados de reanálise, conforme descrito na Parte 1.

No estudo em questão, utilizou-se a RNA otimizada na Parte 1 com as correlações máximas entre as variáveis de entrada e saída nos pontos $\mathbf{1}$ e $\mathbf{2}$ de Reanálise. Para o critério de parada foi analisado o desempenho de generalização da rede após cada iteração de aprendizagem conforme descrito, também na Parte 1.

\section{RESULTADOS E DISCUSSÃO}

Os resultados obtidos com as informações maregráficas da cidade de Cananéia confirmaram a variabilidade da maré meteorológica ou nível médio do mar no litoral Sudeste, quando comparados com dados de Paranaguá. As análises dos dados maregráficos filtrados de Paranaguá e Cananéia são mostrados na Figura 2, onde se observa o comportamento semelhante do nível do mar filtrado nas duas estações.

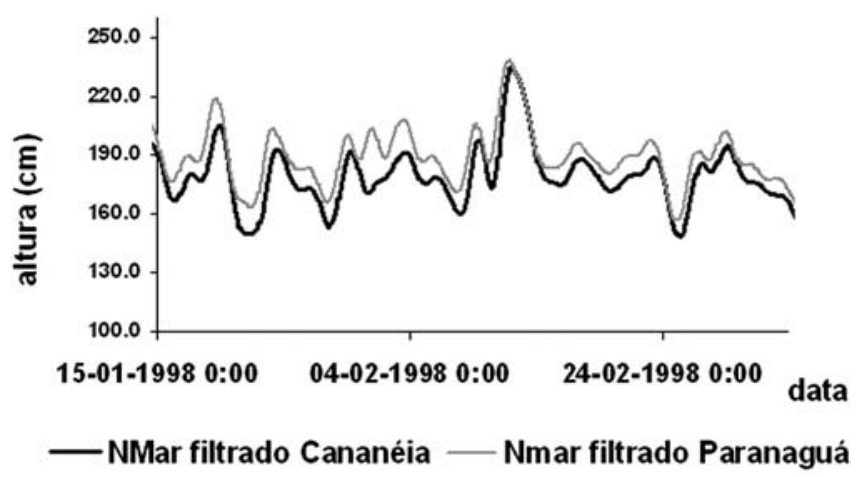

Figura 2 - Variação do nível médio do mar diário em Paranaguá (PR) e Cananéia (SP).

O valor de $93.26 \%$ foi obtido para o cálculo da correlação cruzada entre os dados maregráficos das duas estações. A Figura 3 mostra o gráfico desse resultado para o período descrito.

Devido a alta correlação cruzada entre Paranaguá e Cananéia utilizou-se os dados meteorológicos remotos de reanálise referentes aos pontos 1 (Figura 1) nas simulações com a RNA otimizada na Parte 1, para os dados de Pontal do Sul.

As análises de variância relativa à remoção das altas freqüências mostradas na Tabela 1 para as séries da pressão, tensão zonal e meridional do vento, para os pontos de reanálise, apresentaram valores em torno de $3.15,33$ e $31 \%$, respectivamente. 


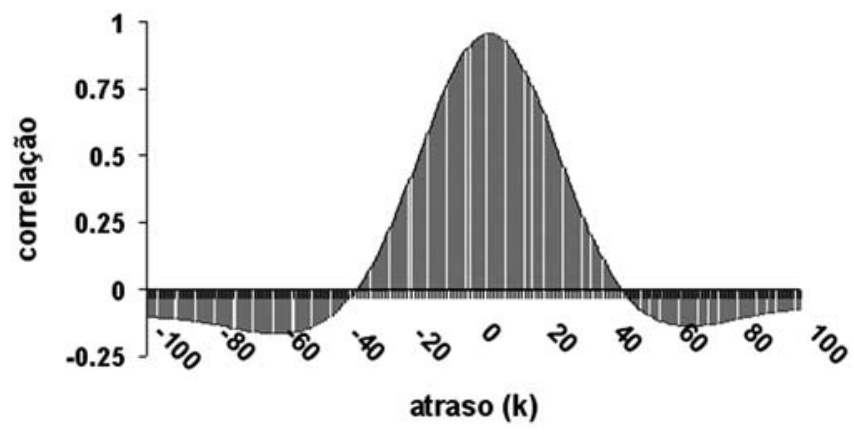

Figura 3 - Correlação cruzada entre o nível do mar filtrado (maré meteorológica) das séries maregráficas de Paranaguá e Cananéia.

Para a estação de superfície, Tabela 2, os valores encontrados foram em torno de 12,71 e $62 \%$, mostrando a influência da fisiografia local.

Considerando-se as correlações máximas dos pontos de reanálise com a estação maregráfica de Paranaguá utilizaram-se como entrada da rede as variáveis com os devidos atrasos, ou seja, pressão (-36h), Tx (-24h), Ty (0), maré meteorológica de $(-18 \mathrm{~h}),(-12 \mathrm{~h}),(-6 \mathrm{~h})$ e vento $(0)$. Essas relações confirmam os resultados encontrados por Mariotti \& Franco, [ca. 2001] para estudos realizados no litoral de Santa Catarina, utilizando o modelo ARIMA com dados convencionais.
As amostras com intervalos de 6 horas entre as observações corresponderam a um total de 2.521 pares de entrada/saída. Desse conjunto de dados selecionou-se $50 \%$ para treinamento, $25 \%$ para verificação e $25 \%$ para teste, conforme Parte 1 .

\section{Simulação para 6 horas $(t=0)$}

Os dados de Reanálise foram utilizados para avaliar o comportamento da série prevista com informações meteorológicas oriundas de pontos próximos à estação maregráfica, observando-se as influências inerentes a esses dados.

A meta de convergência do erro de predição, com os dados de Reanálise, foi a mesma adotada na Parte 1. Para o treinamento e verificação da RNA definiu-se a qualidade do resultado considerando-se a melhor performance possível para ambos. O Quadro 1 mostra a convergência do erro para as diferentes épocas adotadas. Como na Parte 1, o melhor desempenho foi também alcançado com 700 épocas, ocorrendo uma estabilização do algoritmo backpropagation.

Quadro 1 - Desempenho da rede de acordo com o número de épocas.

\begin{tabular}{|c|c|c|}
\hline Épocas & Erro de treinamento & Erro de verificação \\
\hline 100 & 0,022149 & 0,021136 \\
\hline 500 & 0,008906 & 0,008780 \\
\hline 700 & 0,008171 & 0,008567 \\
\hline
\end{tabular}

Tabela 1 - Resultados estatísticos com dados de reanálise nos pontos 1 (pressão) e 2 (vento).

\begin{tabular}{ccccccc}
\hline Variável & Máximo & Médio & Mínimo & Variância & Desvpad & Filtro \\
\hline P & 1030,2 & 1015,3 & 1001,9 & 22,54 & 4,74 & \\
P Filt & 1029,4 & 1015,3 & 1003,5 & 21,83 & 4,67 & $3,15 \%$ \\
\hline Tx & 362,5 & $-11,83$ & $-357,38$ & 1752,84 & 41,86 & \\
Tx Filt & 279,89 & $-10,75$ & $-232,92$ & 1166,47 & 34,15 & $33,45 \%$ \\
Ty & 275,87 & 2,81 & $-178,04$ & 1417,53 & 37,65 & \\
Ty Filt & 226,58 & 2,87 & $-93,66$ & 977,41 & 31,26 & $31,04 \%$ \\
\hline
\end{tabular}

Tabela 2 - Resultados estatísticos com dados meteorológicos de Pontal do Sul

\begin{tabular}{ccccccc}
\hline Variável & Máximo & Médio & Mínimo & Variância & Desvpad & Filtro \\
\hline P & 1033 & 1016 & 999 & 28,09 & 5,29 & \\
P Filt & 1031 & 1016 & 1002,9 & 24,75 & 4,98 & $11,90 \%$ \\
\hline Tx & 96,76 & $-12,4$ & $-360,82$ & 905,19 & 30,08 & \\
Tx Filt & 36,51 & $-6,72$ & $-176,76$ & 254,56 & 16,26 & $71,87 \%$ \\
\hline Ty & 371 & 11,32 & $-260,77$ & 1203,94 & 34,69 & \\
Ty Filt & 161,16 & 8,53 & $-60,44$ & 446,88 & 21,13 & $62,88 \%$ \\
\hline
\end{tabular}


A Tabela 3 mostra os resultados estatísticos referentes aos pares selecionados para treinamento, verificação e teste. Verificam-se uma correlação de $99 \%$ em ambas as etapas.

Como na Parte 1, o Quadro 2 mostra os resultados da análise de sensibilidade relativa as variáveis de entrada da RNA, indicando qual entrada é considerada mais importante pela rede adotada. Verifica-se, também como na Parte 1, a forte correlação entre o horário a ser previsto e os atrasos das respostas da maré meteorológica às forçantes atmosféricas nos horários anteriores. As principais variáveis foram, também, as autocorrelações da maré meteorológica nos horários de $6 \mathrm{~h}, 12 \mathrm{~h}$ e $18 \mathrm{~h}$, porém seguidas da pressão, módulo do vento $(\mathrm{V}(\mathrm{t}))$, tensão meridional $\left(\mathrm{T}_{\mathrm{Y}}\right)$, e tensão zonal $\left(\mathrm{T}_{\mathrm{X}}\right)$.

A Figura 4 apresenta a evolução do treinamento e verificação da rede para alcançar a meta de convergência do erro. A curva em preto representa o treinamento e a linha cinza a verificação.

A Figura 5 mostra a fase de treinamento da rede e a saída desejada, verificando-se o desempenho do modelo em representar a maré meteorológica, semelhante ao resultado obtido na Parte 1.
Após o treinamento foram apresentados à rede os pares relativos ao teste ou validação, conforme descrito na Parte 1, no sentindo de se avaliar a capacidade de generalização da rede na predição da maré meteorológica com os dados de reanálise.

A Figura 6 apresenta os resultados obtidos com a rede treinada, onde se observa a saída desejada (maré meteorológica) e a prevista pela rede neural. Verifica-se que as duas curvas mantêm o comportamento semelhante ao obtido com os dados da estação de superfície.

\section{Simulações para $12(t=6), 18(t=12)$ e $24(t=18)$ horas.}

Foram realizadas, também simulações da maré meteorológica para as defasagens de $12 \mathrm{~h}, 18 \mathrm{~h}$ e $24 \mathrm{~h}$ considerando-se a mesma arquitetura de rede, bem como os parâmetros ajustáveis da rede conforme descrito na Parte 1.

Os resultados estatísticos dessas simulações são mostrados nas Tabelas 4(a) a 4(c). Na Tabela 4(a) verifica-se que o desempenho da rede foi mantido para a simulação de 12 horas em relação à de 6 horas, com correlações em torno de $98 \%$. Nas Tabelas 4(b) e 4(c) observa-se que os valores de correlação

Tabela 3 - Resultados estatísticos referentes à previsão para 6 horas.

\begin{tabular}{lccc}
\hline & Treinamento & Verificação & Teste \\
\hline Média & 179,1658 & 187,3546 & 181,4642 \\
Desvio padrão & 17,6604 & 16,96314 & 16,73424 \\
Erro Médio & $-0,07386$ & $-0,03758$ & $-0,15857$ \\
Erro do desvio padrão & 0,81603 & 0,903822 & 0,93676 \\
Correlação & 0,998932 & 0,998586 & 0,99846 \\
\hline
\end{tabular}

Quadro 2 - Análise de sensibilidade.

\begin{tabular}{|c|c|c|c|c|c|c|c|}
\hline & Pres(-36) & Tx(-30) & Ty(t) & MM(-18) & MM(-12) & MM(-6) & V(t) \\
\hline Ordem & 4 & 7 & 6 & 3 & 2 & 1 & 5 \\
\hline Erro & 0,933615 & 0,811847 & 0,891543 & 15,78379 & 44,67187 & 46,93925 & 0,911074 \\
\hline Taxa & 1,032865 & 0,811847 & 0,98632 & 19,27107 & 54,54169 & 57,31003 & 1,007928 \\
\hline
\end{tabular}

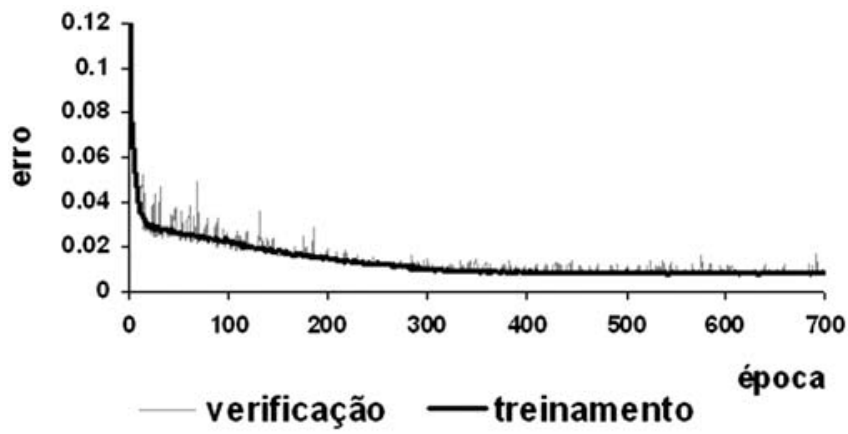

Figura 4 - Evolução do treinamento e verificação da RNA.

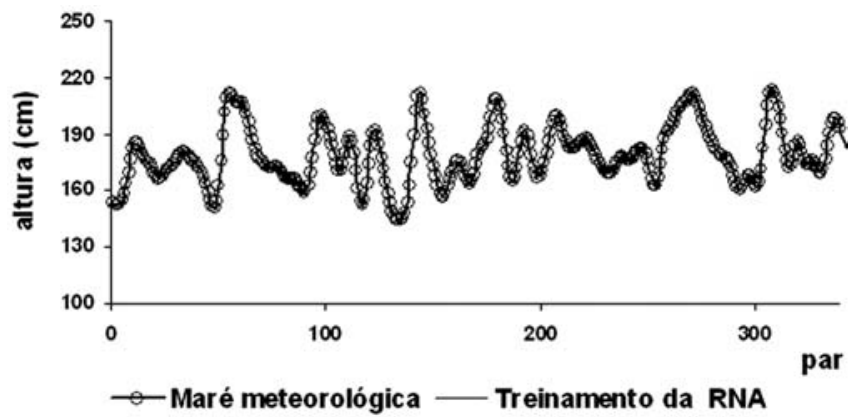

Figura 5 - Gráficos da saída da rede e saída desejada na fase de treinamento 


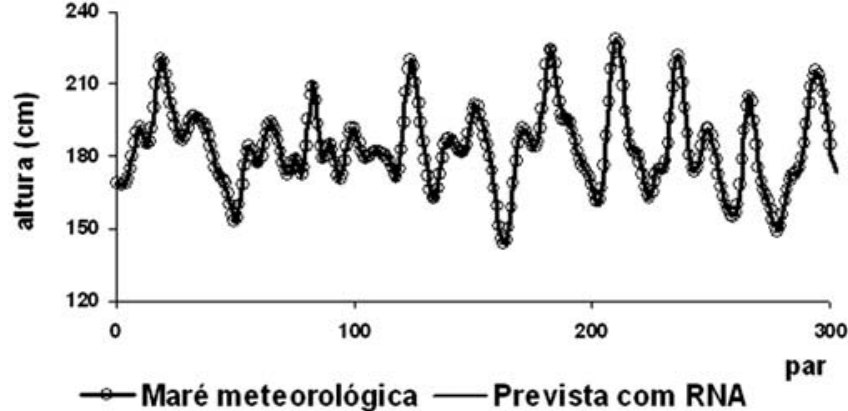

Figura 6 - Gráficos da saída da rede e saída desejada na fase de teste. encontrados para 18 e 24 horas foram semelhantes aos encontrados para a estação de superfície (Parte 1), em torno de $92 \%$ e $78 \%$, respectivamente.

Acredita-se que os valores de correlação encontrados para $18 \mathrm{~h}$ e $24 \mathrm{~h}$ podem estar também relacionados aos fatores descritos na Parte 1.

A Tabela 5 mostra os valores máximos, médios e mínimos do erro para o treinamento, verificação e teste entre, a saída da rede e a saída desejada em relação aos horários das referidas simulações. Esses resultados foram semelhantes aos encontrados para a estação de superfície. Observa-se, também um aumento nos erros máximos e mínimos nas três etapas para os horários relativos à previsão de 18 h e 24 h, estando em concordância com os valores das correlações para os mesmos horários apresentadas nas tabelas anteriores.

Tabela 4 - Resultados estatísticos referentes à previsão.

\begin{tabular}{lccc}
\hline \multicolumn{4}{c}{ (a) $\mathbf{1 2}$ horas. } \\
\hline & Treinamento & Verificação & Teste \\
\hline Média & 179,3755 & 187,2006 & 181,1243 \\
\hline Desvio padrão & 17,73482 & 16,92447 & 18,19546 \\
\hline Erro Médio & $-3,79987$ & $-3,5911$ & $-3,86049$ \\
\hline Erro do desvio padrão & 2,754362 & 3,046132 & 3,793456 \\
\hline Correlação & 0,987872 & 0,983681 & 0,980787 \\
\hline & (b) $\mathbf{1 8}$ horas & & \\
\hline Média & 179,4194 & 187,1817 & 181,4076 \\
\hline Desvio padrão & 17,73681 & 16,92767 & 16,69878 \\
\hline Erro Médio & $-0,2518$ & 0,179352 & $-0,97281$ \\
\hline Erro do desvio padrão & 5,733315 & 6,325062 & 6,652299 \\
Correlação & 0,946318 & 0,927577 & 0,91905 \\
\hline & (c) 24 horas & & \\
\hline Média & 179,4563 & 187,1489 & 181,1537 \\
\hline Desvio padrão & 17,72976 & 16,9243 & 16,68865 \\
\hline Erro Médio & $-7,69265$ & $-8,04257$ & $-8,63694$ \\
\hline Erro do desvio padrão & 9,006542 & 10,06083 & 10,39033 \\
\hline Correlação & 0,861641 & 0,80641 & 0,786256 \\
\hline
\end{tabular}

Tabela 5 - Erro de treinamento, verificação e teste entre a saída da RNA e o alvo.

\begin{tabular}{|c|c|c|c|c|c|c|c|c|c|}
\hline \multirow{2}{*}{ Predição } & \multicolumn{3}{|c|}{ Treinamento } & \multicolumn{3}{|c|}{ Verificação } & \multicolumn{3}{|c|}{ Teste } \\
\hline & Máx & Méd & Mín & Máx & Méd & Mín & Máx & Méd & Mín \\
\hline$t=0(6 h)$ & 3,10 & $-0,07$ & $-3,22$ & 2,83 & $-0,03$ & $-3,53$ & 3,50 & $-0,14$ & $-3,67$ \\
\hline$t=6(12 h)$ & 19,44 & $-0,25$ & $-24,43$ & 16,28 & 0,13 & $-23,78$ & 23,44 & $-0,91$ & $-23,61$ \\
\hline $\mathrm{t}=12(18 \mathrm{~h})$ & 15,21 & $-3,64$ & $-27,84$ & 11,84 & $-3,74$ & $-27,18$ & 18,64 & $-4,38$ & $-28,2$ \\
\hline $\mathrm{t}=18(24 \mathrm{~h})$ & 22,61 & $-7,68$ & $-46,18$ & 19,71 & $-8,0$ & $-48,24$ & 26,9 & $-8,61$ & $-46,92$ \\
\hline
\end{tabular}


As freqüências dos erros entre os valores previstos e observados das alturas da maré meteorológica para as defasagens de 6 h, 12 h, 18 h e 24 h com dados da estação de superfície e reanálise mostraram resultados satisfatórios para ambas as fontes de dados. Os histogramas das Figuras 7(a) a 7(d) apresentam as freqüências dos erros para cada horário previsto com dados de Pontal do Sul, considerando-se os 630 pares de entrada/saída utilizados para teste no modelo neural. Verificou-se que o modelo apresentou valores de previsão da maré meteorológica, para os horários de 6 h e 12 h, em torno de -3.52 a $3.14 \mathrm{~cm}$ e -11.81 a $10.29 \mathrm{~cm}$, respectivamente, subestimando em 52.38\% as alturas previstas para ambos os horários. Para a previsão de $18 \mathrm{~h}$ e $24 \mathrm{~h}$ os valores ficaram entre -22.57 a 20.94 cm e -33.67 a $28.21 \mathrm{~cm}$, subestimando em $38.73 \%$ e $42.38 \%$ as alturas previstas, respectivamente.

Os gráficos de distribuição dos erros das Figuras 8(a) a 8 (d) mostram uma concentração de valores dos erros nas faixas entre -1.92 a $1.81 \mathrm{~cm}$ para 6 horas $(96.98 \%),-6.51$ a $5.87 \mathrm{~cm}$ para

a)

c)

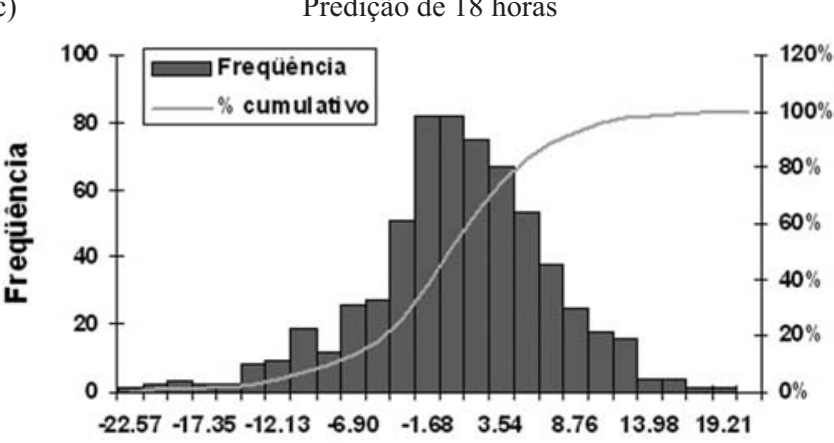

Erro
12 horas (96.19\%), -13.86 a $12.81 \mathrm{~cm}$ para 18 horas $(93.96 \%)$ e -16.34 a $20.79 \mathrm{~cm}$ para 24 horas $(96.50 \%)$.

Para os dados de reanálise, considerando-se o mesmo número de pares de entrada/saída, foram verificados valores das alturas previstas, em torno de -3.67 a $3.50 \mathrm{~cm},-23.61$ a 23.44 cm, -28.20 a 18.64 e -45.79 a $27.50 \mathrm{~cm}$ para $6 \mathrm{~h}, 12 \mathrm{~h}, 18 \mathrm{~h} \mathrm{e}$ $24 \mathrm{~h}$, respectivamente.

Os histogramas das Figuras 9(a) a 9(d) mostram as freqüências dos erros para os diferentes horários para as simulações com dados de reanálise. Para os horários de 6 h e 12 h o modelo superestimou as alturas em, aproximadamente, $54 \%$ e para as previsões de $18 \mathrm{~h}$ e $24 \mathrm{~h}$ houve uma subestimação das alturas em torno de $76 \%$ e $70 \%$, respectivamente.

Os gráficos de distribuição dos erros das Figuras 10(a) a 10(d) mostram uma concentração de valores nas faixas entre -1.95 a $1.78 \mathrm{~cm}$ para 6 horas $(96.49 \%),-12.31$ a $12.15 \mathrm{~cm}$ para 12 horas $(94.44 \%),-15.96$ a $11.15 \mathrm{~cm}$ para 18 horas $(96.82 \%)$ e -22.33 a $15.77 \mathrm{~cm}$ para 24 horas $(94.44 \%)$. b)

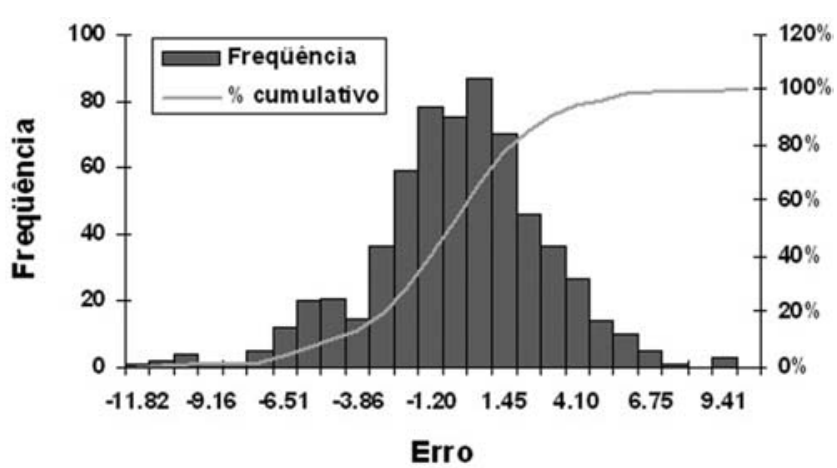

d)

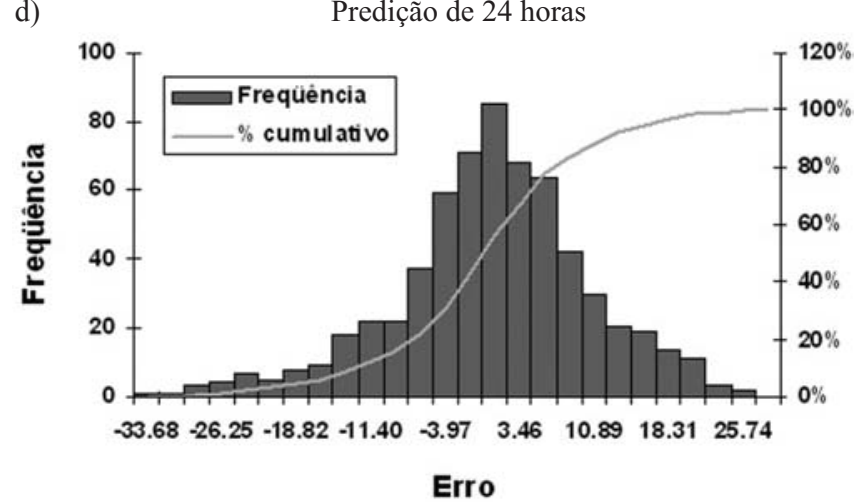

Figura 7 - Histogramas relativos aos valores dos erros entre a saída da rede e o alvo com dados da estação de Pontal do Sul. 

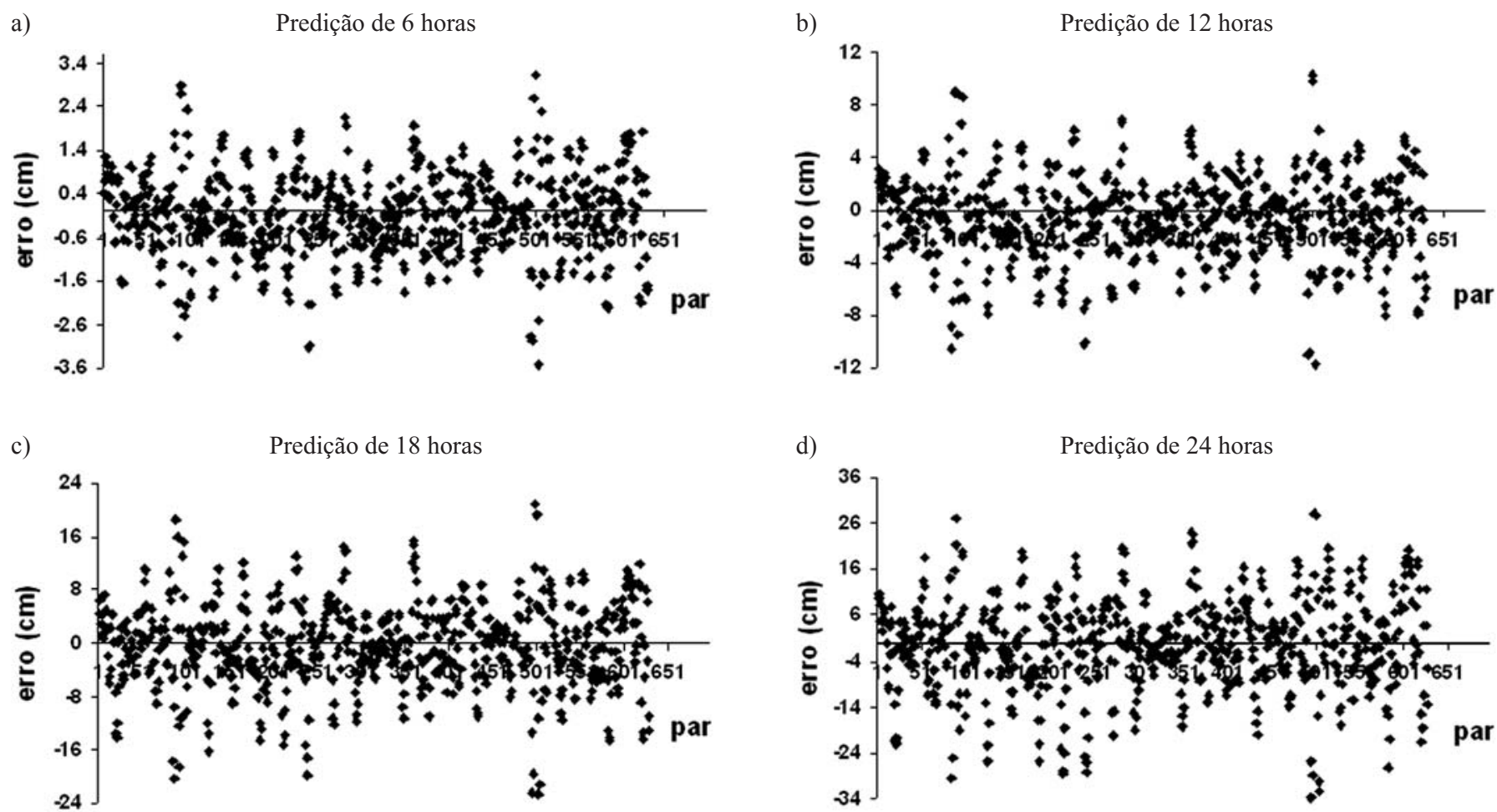

Figura 8 - Gráficos da distribuição dos erros entre a saída da rede e o alvo com dados de Pontal do Sul.

a)
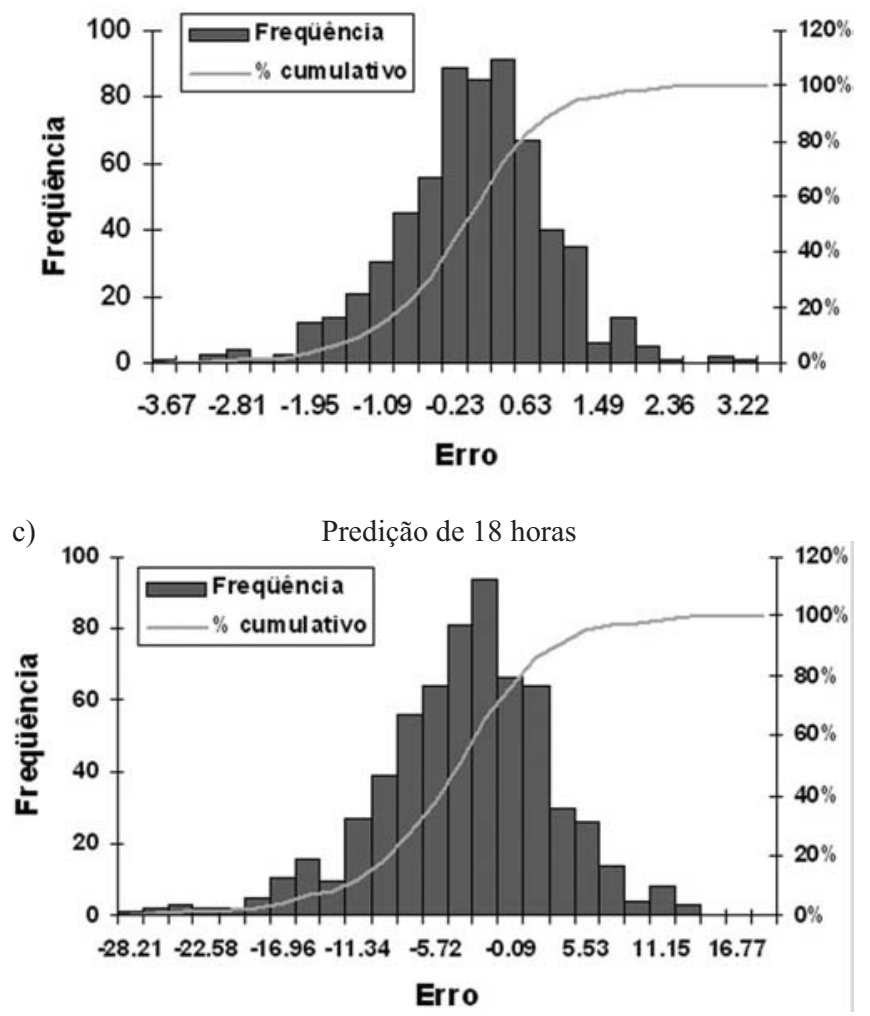

b)

Predição de 12 horas

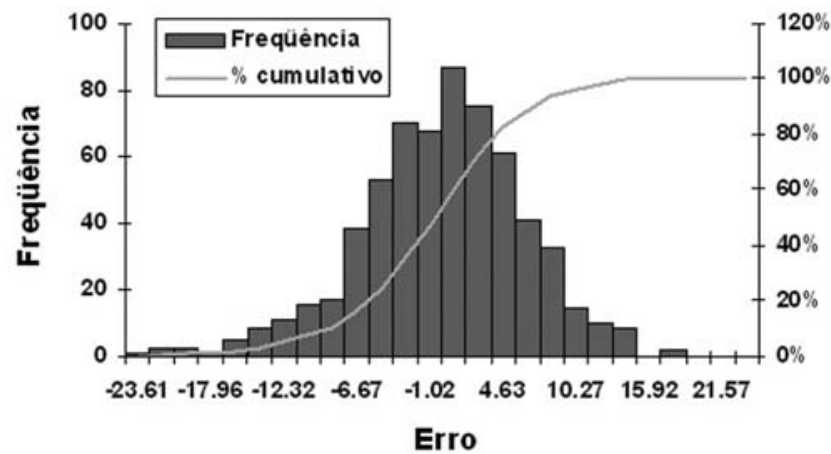

d)

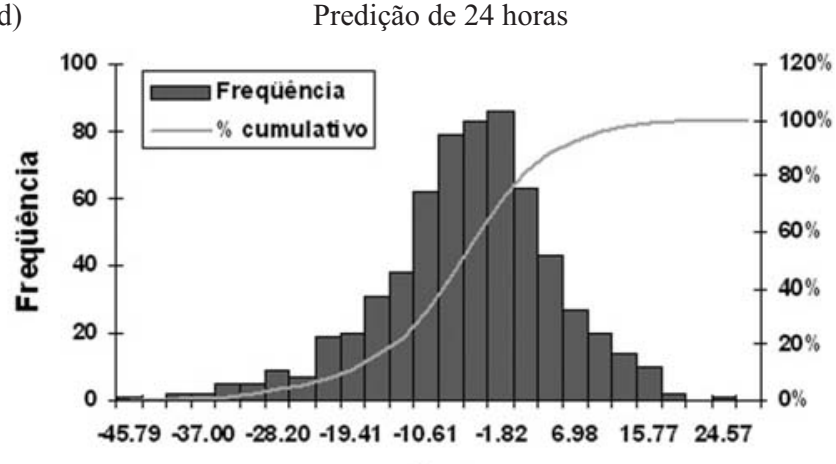

Erro

Figura 9 - Histogramas relativos aos valores dos erros entre a saída da rede e o alvo com dados de Reanálise. 
a)
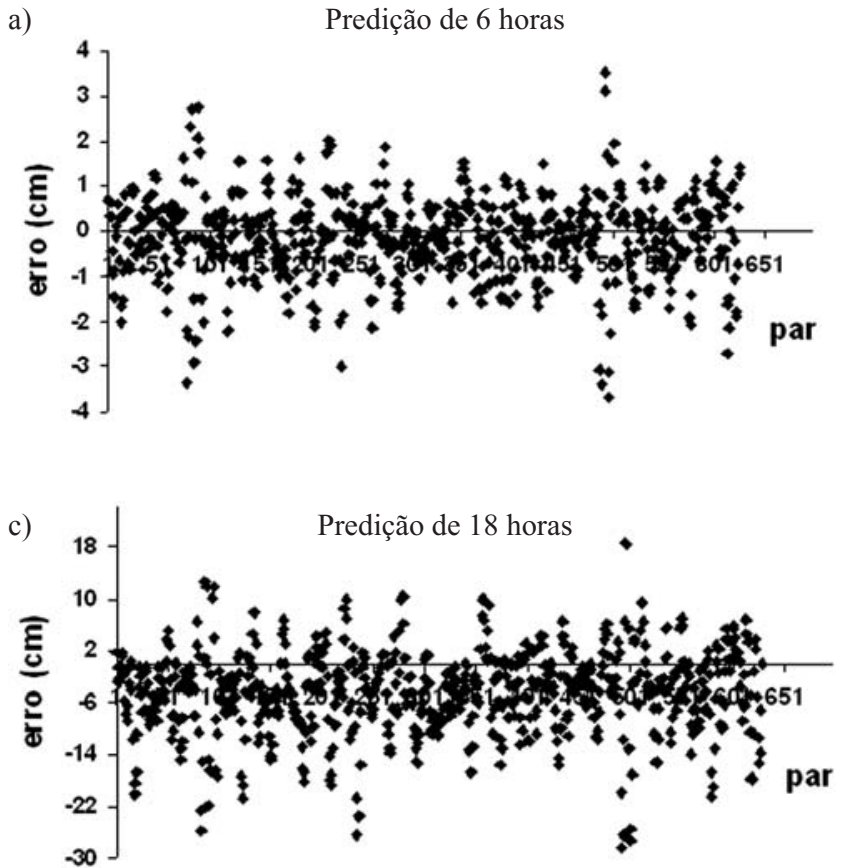

b)
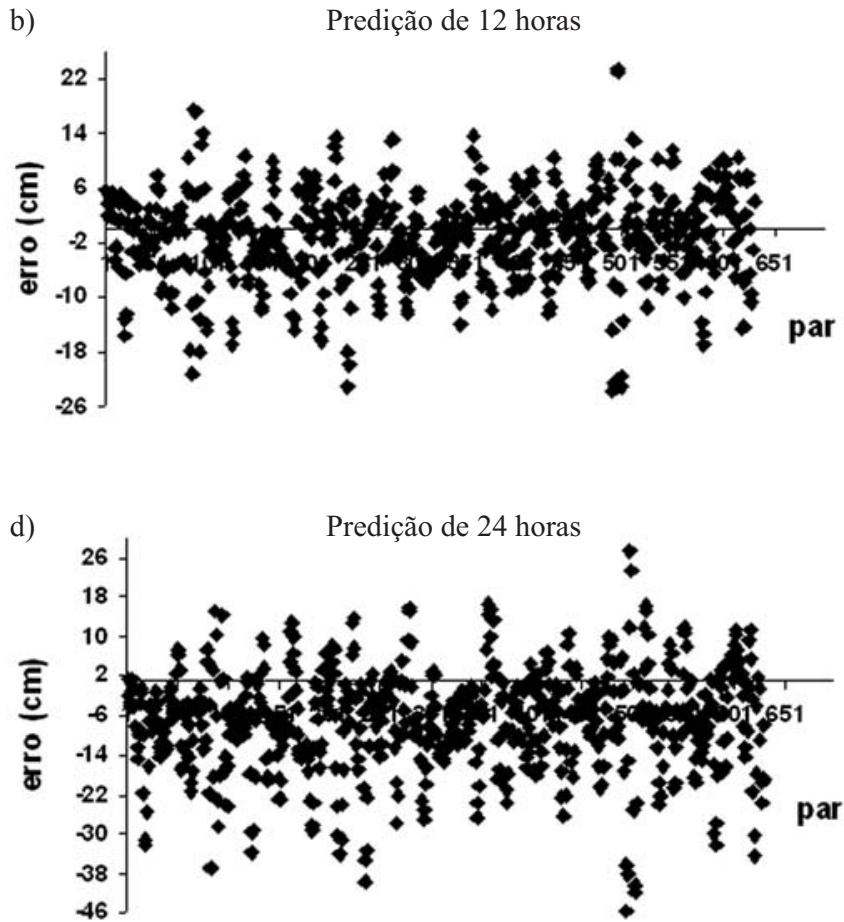

Figura 10 - Gráficos da distribuição dos erros entre a saída da rede e o alvo com dados de reanálise.

\section{CONCLUSÕES}

Comparando as duas fontes de dados meteorológicos, verificou-se que a utilização dos dados de reanálise, na predição da maré meteorológica, foi mais adequada, uma vez que os pontos 1 e 2 situam-se na região oceânica próxima ao litoral Sudeste.

As análises no domínio da freqüência, para a estação de superfície e reanálise, mostraram valores elevados de energia e coerência para eventos com periodicidade, em torno de 5 dias. Esses valores podem ser justificados pela passagem de sistemas atmosféricos migratórios que influenciam a variabilidade da maré meteorológica no ponto em questão.

Os dados de reanálise selecionados na área marítima, próximos à estação maregráfica, possibilitaram a comparação entre os resultados encontrados com os dados da estação de superfície. Verificou-se assim, que as relações existentes entre os fenômenos atmosféricos e as respostas do mar a esses fenômenos são muito mais evidenciadas com as informações oriundas da região oceânica, próxima à estação maregráfica. Verificou-se ainda que, com as informações de reanálise foi possível estabelecer as relações entre os eventos remotos que afetam a maré meteorológica, como verificado no ponto $\mathbf{2}$ ao sul de Paranaguá. Neste ponto a componente meridional do vento possui valores energéticos bastante elevados, mostrando a influência da orientação da costa no local em questão.
As correlações da maré meteorológica com a pressão atmosférica na estação de superfície e no ponto 1 de reanálise foram bem semelhantes, em torno de $43 \%$, para atrasos, de 42 horas e 36 horas, respectivamente, mostrando que a região costeira de Paranaguá responde de maneira similar às flutuações desta variável nos processos atmosféricos de baixa freqüência. Acredita-se que estes atrasos, com relação à pressão, podem estar relacionados à localização da estação maregráfica, influenciados pela fisiografia da Baía de Paranaguá, a qual interfere na resposta do nível do mar costeiro.

Os resultados similares apresentados pela rede na predição da maré meteorológica para uma defasagem de 6 horas, utilizandose dados de superfície e de reanálise, demonstraram a possibilidade de utilização dos dados de reanálise na falta de informações meteorológicas próximas às estações maregráficas, principalmente, em litorais onde o comportamento deste fenômeno é semelhante.

Os resultados da predição com dados de reanálise, obtidos com a RNA desenvolvida na Parte 1, mostraram valores semelhantes aos da estação de superfície. As predições realizadas para períodos mais longos (18 h e $24 \mathrm{~h}$ ) apresentaram resultados de correlações inferiores aos verificados para a defasagem de $6 \mathrm{~h}$ e $12 \mathrm{~h}$ para ambos os dados.

Os dados de reanálise além de traduzirem melhor as variações dos fenômenos atmosféricos em baixas freqüências, na área oceânica, são fontes de informações numa região onde a carência de dados ainda é substancial. 


\section{AGRADECIMENTOS}

Os autores agradecem ao Centro de Estudos do Mar da Universidade Federal do Paraná e ao Centro de Hidrografia da Marinha pelo fornecimento dos dados meteorológicos e maregráficos. Agradecemos, também aos revisores anônimos pelas sugestões e críticas. $\mathrm{O}$ primeiro autor agradece à CAPES pelo apoio financeiro.

\section{REFERÊNCIAS BIBLIOGRÁFICAS}

CALÔBA, L. P. "Introdução ao uso de redes neurais na modelagem de sistemas dinâmicos e séries temporais". In: Livro de Minicursos do Congresso Brasileiro de Automática, 14. Natal, 2002.

FILIPPO, Alessandro Mendonça Variabilidade do Nível do Mar em Função de Eventos Meteorológicos de Baixa Freqüiência. 2003. 100 f. Tese (Doutorado em Geoquímica Ambiental) - Universidade Federal Fluminense, Niterói, 2003.

FRANCO, A. S. Marés-programas para previsão e análise: Manual do Sistema PAC. São Paulo: Cotia, 1992.

KISTLER, ROBERT ET AL., 2001, THE NCEP/NCAR 40 Year Reanalysis Project, Bull. Am. Meteorol. Soc., v. 77, n. 3, pp. 437-471.

KALNAY, Eugenia, et al., 2001, The NCEP/NCAR 50 Year Reanalysis: Monthly Means CD-ROM and Documentation, Bull. Am. Meteorol. Soc., v. 82, n. 2, pp. 247-267.
MESQUITA, Afranio Rubens de. Marés, Circulação e Nível do Mar na Costa Sudeste do Brasil. Disponível em: http:// www.mares.io.usp.br/agn/51/una/una.html. Acesso em 25 set. 2003

MARIOTTI, Mara Terezinha, FRANCO, Davide. Análise Arima da Resposta do Nível do Mar à Forçantes Atmosféricas Locais: Florianópolis: LAHIMAR/UFSC, 2001.

MOREtTin, P. A., TOlOI, C. M. C. Previsão de Séries Temporais. 2. ed. São Paulo: Instituto de Matemática Pura e Aplicada - IMPA, 1987. 183 p.

PATRICK, A. R., COLLINS, W. G., TISSOT, P. E., DRIKTIS, J., MICHAUD, P., COX, D. T. Use of the NCEP Mesoeta Data in a Water Level Predicting Neural Network. In: CONFERENCE ON WEATHER ANALYSIS AND FORECASTING, 19., 2002., AMS CONFERENCE ON NUMERICAL WEATHER PREDICTION, 15., 2002. Proceeding... Am. Meteorol. Soc., 2002.

TRUCCOLO, E. C. Maré Meteorológica e Forçantes Atmosféricas Locais em São Francisco do Sul. 1998. 100 f. Dissertação (Mestrado em Engenharia Ambiental) - UFSC, Florianópolis, 1998.

UAISSONE, A. J. R. Influência das Forçantes Atmosféricas em Mesoescala sobre o Nível Médio do Mar em Piraquara, RJ. 2004. 138 f. Dissertação (Mestrado em Engenharia Oceânica) - COPPE/UFRJ, Rio de Janeiro, 2004. 